\title{
Beyond Geographical and Cultural Barriers: The Concept of a Virtual Gallery for Arts, Design \& Architecture Schools in Saudi Arabia
}

\author{
Abeer Alawad1, Mohammed Aljoufie ${ }^{2}$, Alok Tiwari², Lamya Daghestani ${ }^{3}$ \\ ${ }^{1}$ Department of Housing, Interior Design and Furniture, Faculty of Home Economics, King Abdulaziz University, \\ Jeddah, Saudi Arabia \\ ${ }^{2}$ Department of Urban and Regional Planning, Faculty of Environmental Design, King Abdulaziz University, \\ Jeddah, Saudi Arabia \\ ${ }^{3}$ Department of Computer Science, Faculty of Computing and Information Technology, \\ King Abdulaziz University, Jeddah, Saudi Arabia \\ Email: aalawad@kau.edu.sa,maljufie@kau.edu.sa,atwari@kau.edu.sa, Idaghestani@kau.edu.sa
}

Received 10 September 2015; accepted 13 November 2015; published 16 November 2015

Copyright (C) 2015 by authors and Scientific Research Publishing Inc.

This work is licensed under the Creative Commons Attribution International License (CC BY).

http://creativecommons.org/licenses/by/4.0/

(c) (i) 0pen Access

\begin{abstract}
The aim of this paper is to examine the advantages and disadvantages of a virtual gallery as a substitute for the Saudi Arabian schools of higher education in Arts, Design \& Architecture which frequently organise exhibitions. Virtual galleries provide new opportunities for architects, designers, artists and experts of other disciplines to lay foundation for new social networks. These networks may establish interdisciplinary knowledge collaborations beyond global geographical barriers. Additionally, it will be an excellent opportunity for students at Saudi Arabian universities to lower the cultural barriers that separate male and female students. Virtual galleries can enrich students' learning, enhance professional skills and also offer savings in term of practical costs (time, money and efforts) required to visit physical exhibitions.
\end{abstract}

\section{Keywords}

Architecture, Interior Design, Arts, Virtual Gallery, Social Network, Exhibition

\section{Introduction}

Exhibition, demonstration, showcasing and public displays are important requirements for Art and Design stu-

How to cite this paper: Alawad, A., Aljoufie, M., Tiwari, A., \& Daghestani, L. (2015). Beyond Geographical and Cultural Barriers: The Concept of a Virtual Gallery for Arts, Design \& Architecture Schools in Saudi Arabia. Art and Design Review, 3, 87-93. http://dx.doi.org/10.4236/adr.2015.34012 
dents and professionals (Burton, 2006). Nevertheless appropriate spaces to fulfill this requisite are limited and this lack has led to a need for alternatives of physical presentation for arts and design projects.

Intense advancement in Information and Communication Technology (ICT), pervasive computing and the digital media has entirely changed the exhibition tendencies of artifacts by introducing a virtual museum or virtual gallery. This paper proposes to establish a virtual gallery for the students of Saudi Arabian Universities by thoughtfully analyzing advantages and disadvantages associated with this medium.

\section{Virtual Gallery: Definition}

In absence of a proper definition for a virtual gallery the phenomenon could be traced back to virtual museums. It was in the 1960s when a French cultural theorist Andre Malraux first advocated the idea of a museum without walls. In his work "Le musee imaginaire" (literally translated as the imaginary museum). Malraux described the shift in how art was studied, understood and taught. Sadly he died in 1976 so he did not get to see the emergence of the Internet which has allowed a colossal "musee imaginaire" to surface, beyond Malraux's original ideas. Malraux regarded the art museum as art's ideal location and this can be seen today with the digital era and the field of new possibilities for the displaying of art (Ahearne, 2004). Tsichritzis \& Gibbs (1991) introduced the concept of virtual museums as a means to overcome the limitations of real museums and to increase user satisfaction and experience. Technological advances have provided society with the development of unique interactive abilities.

A virtual museum could be seen as a systematic and organised collection of digital objects over multimedia offering flexibility to visitors for communication and interaction as per their needs and interests. Objects are available through pervasive computing and have no real space of place (Bonis et al., 2009; Schweibenz, 1991). It could be a digital aggregation of artifacts over cyberspace or available in digital format via PC, PDA or CDROM as an extension to physical displays which are available in an entirely virtual format (Styliani et al., 2009). Virtual galleries are viewed as an effective alternative to a real visit; they hold greater importance for the visitors whose access to the real gallery sites is outlawed (Vosinakism \& Xenakis, 2011). In a virtual museum, a visitor can accomplish examine, explore, learn and interact with a digital collection of artifacts within a single or multiuser environment (Sylaiou et al., 2009) without any restrictions related to time and space. Furthermore, it can enrich visitors’ societal, scholastic and entertainment understanding (Dede \& Ketelhut, 2003).

Hence, the reflection that emerged from aforesaid definitions reveals that a virtual gallery showcases artifacts in a multimedia format available online through various computing instruments by overcoming many restrictive barriers. This offers flexible prospects to the visitors with regards to their level of knowledge related to artifacts.

\section{Application Areas}

Most commonly virtual galleries are used to display archaeological artifacts, which are known as virtual museums for instance, “The Herbert Virtual Museum” (Petridis et al., 2013). Virtual museums are also believed to be supportive for the teaching and learning of disciplines related to history and culture (Panina, 2013; Ulusoy, 2010). There are examples where virtual museums are utilised in a language (English) curricula for enhancing multimodal meaning making in a collaborative manner; designed and implemented by students (Caroline et al., 2011).

Maryse \& Marion (2007) studied 125 Canadian teachers and found that they were increasingly using the Internet and virtual museums in their primary and secondary teaching. They used museum websites and galleries as a supplementary teaching resource for History and social studies. The Nah Tah Wahsh School (2000) in Michigan developed a visual museum project where the students made choices about what they wanted to study. This proved to be an ideal way to ensure a student-centered constructivist-learning environment in schools. Constructivism proposes that knowledge is constructed through the physical interaction with the real world and therefore this has promising potential for education. Numerous applications can be showcased through a virtual gallery or museum over cyberspace, especially in the educational disciplines that are highly dependent to visualization or re-construction of historic artifacts.

The importance of virtual galleries has been researched in Art and Design disciplines especially for the sharing of creations, wider collaboration and enhancing teaching/learning processes (Lu, 2008; Burton, 2010; Carmo \& Claudio, 2013). Art, Design and Architecture courses are traditionally taught with PowerPoint presentations of images and textbooks. A virtual gallery will enhance traditional pedagogical methods by ensuring viewing is 
active and no longer passive. According to Omale et al., the development of 3-D virtual elements is an exciting trend with the potential to enable global cultural diffusion (Omale et al., 2009). Ulusoy's study aimed to determine whether the attitudes of open education students would be changed by the implementation of a virtual museum application. After viewing various resources and virtual displays the 20 students within the experimental group had a favourable opinion of the virtual museum application. The results revealed that using virtual museums in teaching History enhanced students' motivation and conceptual understanding (Ulusoy, 2010). Students appreciated the rich visual images they viewed: an exhibit can be manipulated by rotating to gain a clear perspective. This manipulation is not possible using static images in textbooks. In conclusion, the virtual museum application enabled the students to immerse themselves within the topics they were studying; participate more actively in their lessons and subsequently this made the lessons more productive.

\section{Advantage of Virtual Gallery Applications}

Enormous developments in Information and Communication Technology enabled Art and Design schools to increase their hi-tech visualisation. There are numerous inherited advantages of virtual gallery applications. It has long been realized that virtual galleries can increase the degree of interactions in manifold (Sánchez et al., 1997). While feedbacks from visitors and peers are among other important benefits (Lu, 2008) continuous advertisements of self-identity and self-expression in the form of photographs, avatars, voice messages or texts are possible through virtual galleries even anonymously (Second Life, 2015; Zoneta, 2010). These galleries even have the ability to overcome spatio-temporal constraints existing in physical showcasing (Vosinakism \& Xenakis, 2011; Burton, 2010). In virtual museums there are no limitations regarding display cases and extending/altering museums: instant change to a collection is possible. This alleviates issues with storage, presentation and protection of artifacts.

Opening discussion and critiques are well embedded in virtual galleries through higher interactions (Burton, 2010). These platforms have a greater role to play in utilising artistic skill and developing the potential of the young generation. Social media such as Facebook, Twitter, Flicker, YouTube and many more can also enhance the learning environment by combining technological knowledge with designing skills as well as improvements in the quality of instructions (Solina, 2014; Burton, 2010; Lu, 2008). It has full commercial abilities as some websites offer the virtual marketplace over cyberspace to sell the designs (Artsonia, 2014). Besides 2D representation of artifacts, virtual galleries provide simulated 3D artifacts to give the feeling of a complete virtual reality (Solina, 2014; Carmo, 2013; Ullrich \& Zara, 2002). Replicating demolished historic buildings and constructions along the basis of available pictures and textual descriptions; simulations of ancient environments and understanding of chronological architectural evolution is possible in a virtual environment (Carmo, 2013).

Research has advocated technology use in art curricula especially to overcome cultural limitations; concluding the fact that web-based connectivity enriched with video elements can surely facilitate female students in learning, sharing ideas and finding inspiration (Alawad, 2013). This is particularly pertinent in the higher learning institutions of the Kingdom of Saudi Arabia; where male and female students are separated.

An exhaustive list of the advantages of Virtual Gallery Applications; is presented in Table 1.

\section{Disadvantages of Using a Virtual Gallery}

Besides all its discussed virtues, virtual galleries have not always received positive feedback. The fundamental argument against virtual galleries is its level of accuracy related to possibly misleading artifacts (Ryan, 1996). Critics condemn virtual museums through considering it a place where beauty is just rhetoric. Moreover, critics state that the Internet or cyberspace should be seen as a way into a museum never as an alternative to the real one (Jones, 2009).

In virtual learning environments there is a threat of deserialization of learners (Winslow, 1996), adverse impacts on task centered learning (Grove et al., 1996), absence of efficient evaluation tools (Littman, 1996), risks to long term vision because of extensive and continuous use of Head Mount Display-HMD, quality and reliability of the provisioning virtual environment and lack of reliable research findings (Sánchez et al., 1997).

Additionally, there are myriad technical obstacles that need to be addressed and overcome. Firstly, how can we make sure a visual gallery is compatible with a wide variety of different access devices? Under-privileged countries may lack the infrastructure that is required for this medium. For example, students may not possess smart phones and may have to rely on a computer lab. Additional programming may be necessary to ensure 
Table 1. An exhaustive list of the advantages of virtual gallery applications.

\begin{tabular}{|c|c|c|c|}
\hline \multirow{2}{*}{ Sl. } & \multicolumn{3}{|c|}{ Advantages of Virtual Galleries } \\
\hline & Concept & Advantages & Source \\
\hline 1. & $\begin{array}{l}\text { Edutainment } \\
\text { (Education with } \\
\text { Entertainment) }\end{array}$ & $\begin{array}{l}\text { - Improved learning performance } \\
\text { - Enhance usability and level of interactions } \\
\text { - Revival of unreachable learning experiences } \\
\text { - Stimulates involvements and the range of senses } \\
\text { - Reconstruction and navigation of a ruined environment } \\
\text { - Raise learner accessibility for disabled }\end{array}$ & $\begin{array}{l}\text { (Sanchez et al., } \\
\text { 2013) }\end{array}$ \\
\hline 2. & $\begin{array}{c}\text { Interactive Virtual } \\
\text { Gallery }\end{array}$ & $\begin{array}{l}\text { - Assist visitors of art galleries to examine virtual reality } \\
\text { - Facilitate designers to exhibit their work } \\
\text { - Enable designers for the modelling of a 3D Gallery }\end{array}$ & $\begin{array}{l}\text { (Ullrich \& } \\
\text { Zara, 2002) }\end{array}$ \\
\hline 3. & Art Café & $\begin{array}{l}\text { - Virtual learning environment } \\
\text { - Rich resource and efficient tool } \\
\text { - Peer feedback }\end{array}$ & $(\mathrm{Lu}, 2008)$ \\
\hline 4. & New Media Art & $\begin{array}{l}\text { - Popularity of networking technologies and online virtual community among } \\
\text { youth } \\
\text { - Offer opportunities for art education, art creation, online exhibition and } \\
\text { communication }\end{array}$ & (Liao, 2008) \\
\hline 5. & $\begin{array}{l}\text { Advertisement of } \\
\text { Personal Identity }\end{array}$ & $\begin{array}{l}\text { - Constant availability of photographs to the permanent public by a professional } \\
\text { - Social Capital in the Virtual Community } \\
\text { - Advertisement of self-desires }\end{array}$ & (Zoneta, 2010) \\
\hline 6. & $\begin{array}{l}\text { Web Based Student } \\
\text { Art Galleries }\end{array}$ & $\begin{array}{l}\text { - Ironic and a modern alternative to traditional art galleries } \\
\text { - Overcoming physical constraints involved in art/design exhibitions } \\
\text { - Wider outreach and visibility } \\
\text { - Offer prospects to others to observe, admire and applaud work of student } \\
\text { artists } \\
\text { - Venue for Critique and Discussion } \\
\text { - Confluence of Art and Technology } \\
\text { - Integration platform for art program such as curricula, write-ups, assignments, } \\
\text { - Hesource and materials }\end{array}$ & (Burton, 2010) \\
\hline 7. & $\begin{array}{c}\text { Interactive Virtual 3D } \\
\text { Gallery }\end{array}$ & $\begin{array}{l}\text { - High Quality performance in terms of providing speed, graphics and frequency } \\
\text { of texture mapping } \\
\text { - Richer user interaction through mobile-based accelerometer sensor }\end{array}$ & $\begin{array}{l}\text { (Sinthanayothin } \\
\text { et al., 2012) }\end{array}$ \\
\hline 8. & $\begin{array}{l}\text { Technology in Art } \\
\text { Classroom }\end{array}$ & $\begin{array}{l}\text { - Promote technology use in art curricula } \\
\text { - Solution to cultural limitations (especially for girls) in learning, sharing ideas } \\
\text { and inspiration }\end{array}$ & (Alawad, 2013) \\
\hline 9. & 3D Virtual Exhibition & $\begin{array}{l}\text { - Virtual creation of physical three-dimensional exhibitions or museum } \\
\text { - Facilitate visitors to explore virtual scenario closer to reality } \\
\text { - Supports cultural diffusion } \\
\text { - Reproducing destroyed ancient buildings based on textual description and } \\
\text { images } \\
\text { - Understanding the historical evolution of architectural artifacts } \\
\text { - Simulating ancient environments } \\
\text { - Enriching young learners' educational attainments in a recreational manner }\end{array}$ & $\begin{array}{c}\text { (Carmo \& } \\
\text { Claudio, 2013) }\end{array}$ \\
\hline 10. & Second Life & $\begin{array}{l}\text { - Explore and discover } \\
\text { - Sharing interests and desires through text or voice chat } \\
\text { - Virtual self-representation or "Avatars" } \\
\text { - Thousands of recreational events every day } \\
\text { - Sharing individual artistic expressions with millions of users } \\
\text { - Higher Social Connectivity with third party social media platforms such as } \\
\text { Facebook, Twitter, YouTube, Flickr }\end{array}$ & $\begin{array}{l}\text { (Second Life, } \\
\text { 2015) }\end{array}$ \\
\hline
\end{tabular}




\section{Continued}

\begin{tabular}{cl}
\hline New Media Art & - Opportunity to combine technological knowledge with designing skills \\
Project & - Open source web/software technologies as an enabler such as Drupal, Joomla!, \\
(Slovenian & Typo3, Worldpress \\
Experiences) & - Internet Video Server-IVS interface for linking the real and virtual world \\
& - 30 million artworks from 137 countries by students (kids) artists of 4000 \\
& Schools \\
Artsonia & - Strict observation of Ethical norms \\
& - Space for students' work and lesson plans on arts and design \\
& - Marketing of student's artwork with sharing of profits
\end{tabular}

platform independence. Can the content of the virtual gallery be accessed and interacted with different hardware platforms, operating systems, and versions of software?

Furthermore, some sculptures may be 3-D rotatable and interactive while others may be viewable only as static 2-D images. A proper virtual gallery would require consistent actions and metadata for each of its objects. Examples of such metadata include the ability to enlarge images, play video to a high quality and links to related supplementary material.

Additionally, there are copyright laws, which can prevent users accessing certain artworks and artifacts. Wadsworth Atheneum website has a large online collection exceeding 50,000 works of art and open use rules. Nevertheless, numerous sites censor access to certain works or request payment for viewing. The visual message of the artwork may be censored. This could lead to a situation where some types of art are absent or underrepresented in the Internet. Finally, censorship is an issue as these galleries could be used in countries with strict laws, which restrict the content of what are viewed. This could affect, confuse and disrupt educational goals.

\section{Virtual Gallery Network for Art and Design Students in Saudi Arabian Universities}

After analyzing the pros and cons of virtual galleries, we found that its advantages are much more valuable than the disadvantages and also the disadvantages could be minimized through adoption of appropriate technological solutions. At the primary education level the concept of a virtual gallery is not new as we found that around 700 artistic creations are present from Saudi Arabia at the largest virtual art museum in the world: (Artsoina 2014). Unfortunately no such experiments have been conducted at higher educational institutions. Hence we propose a framework for a virtual gallery for arts and design students of Saudi Arabian universities (Figure 1).

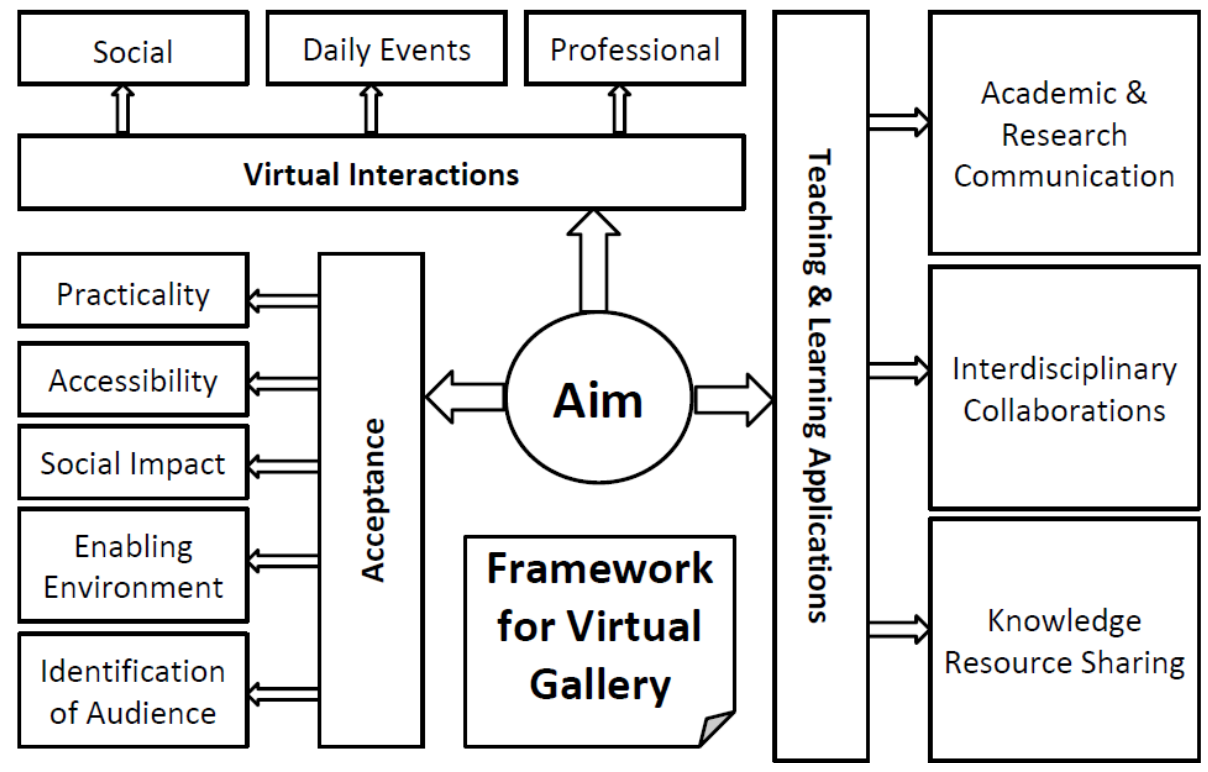

Figure 1. Framework for virtual gallery. 
For the proposed virtual gallery we have to ensure its acceptance in term of practicality, accessibility, social impacts, enabling environment and identification of audience. Secondly, the proposed framework attempts to develop teaching and learning applications aimed at enhanced academic and research communication, improved interdisciplinary collaborations and enriched knowledge and resource sharing. Finally, the target is to accelerate virtual interactions, whether social or professional or daily events; these interactions could be conducted through social media interfaces.

\section{Conclusion}

We establish that the confluence of Arts and Technology in a virtual gallery can offer greater flexibility of interactions, learning, sharing, discussing, critiquing and marketing that can not only solve the challenges from geographical barriers, but also it can be advantageous for female students that cannot interact with male students due to cultural barriers in the real environment. A proposed virtual gallery for the students of Art and Design at Saudi Universities can open new avenues of interaction in a virtual environment for enhanced learning and collaborations, which is especially pertinent in the case of female students.

\section{References}

Ahearne, J. (2004). Between Cultural Theory and Policy: The Cultural Policy Thinking of Pierre Bourdieu, Michel de Certeau and Régis Debray (pp. 138-143). Centre for Cultural Policy Studies.

Alawad, A. (2013). Technologies in the Art Classroom: Using Technologies in Art Classrooms to Overcome Cultural Limitations to Support Teaching and Learning. Journal of Fine and Studio Art, 3, 1-4.

Artsonia (2014). Artsonia Art Museum. http://www.artsonia.com/museum/

Bonis, B., Stamos, J., Vosinakis, S., Andreou, I., \& Panayiotopoulos, T. (2009). A Platform for Virtual Museums with Personalized Content. Multimedia Tools and Applications, 42, 139-159. http://dx.doi.org/10.1007/s11042-008-0231-2

Burton, D. (2006). Exhibiting Student Art: The Essential Guide for Teachers. TC Press.

Burton, D. (2010). Web-Based Students Art Galleries. Art Education, 63, 47-25.

Carmo, M. B., \& Cláudio, A. P. (2013). 3D Virtual Exhibitions. DESIDOC Journal of Library \& Information Technology, 33, 222-235. http://dx.doi.org/10.14429/djlit.33.3.4608

Caroline, M. L. H., Nelson, M. E., \& Wolfgang, M. W. (2011). Design and Implementation of a Student-Generated Virtual Museum in a Language Curriculum to Enhance Collaborative Multimodal Meaning-Making. Computers \& Education, 57, 1083-1097. http://dx.doi.org/10.1016/j.compedu.2010.12.003

Dede, C., \& Ketelhut, D. (2003). Designing for Motivation and Usability in a Museum Based Multi-User Virtual Environment. Proceedings of the American Educational Research Association Conference, Chicago.

Grove, J., Williams, N., \& Hartley, P. (1996). Can Virtual Reality Work in the Classroom? Proceedings of the ICTE, New Orleans, 726-728.

Jones, J. (2009). Museums on the Internet? Get Real. The Guardian. http://www.theguardian.com/artanddesign/jonathanjonesblog/2009/jul/09/museums-internet-future

Liao, C. L. (2008). Avatars, Second Life and New Media Art: The Challenge for Contemporary Art Education. Art Education, 61, 87-91.

Littman, M. (1996). Enhancing Instruction through Virtual Reality. Proceedings of ICTE, New Orleans, 17-20 March 1996, 31-33

Lu, L. F. L. (2008). Art Café Is a 3 Dimensional Virtual Learning Environment. Art Education, 61, 48-35.

Maryse, P., \& Marion, B. (2007). Websites and Virtual History Museums: Educational Strategies Used by Francophone Teachers in Canada. International Journal of Instructional Media, 34, 159-169.

Nah Tah Wahsh School (2000). Virtual Museum Project. http://www.nmai.si.edu/exhibitions/all_roads_are_good/VTStory3.htm

Omale, N., Hung, W. C., Luetkehans, L., \& Cooke-Plagwitz, J. (2009). Learning in 3-D Multiuser Virtual Environments: Exploring the Use of Unique 3-D Attributes for Online Problem-Based Learning. British Journal of Educational Technology, 40, 480-495. http://dx.doi.org/10.1111/j.1467-8535.2009.00941.x

Panina, N., Kazakov, V., Bartosh, N., \& Emelyanov, P. (2013). Virtual Museum in Teaching Subjects in the Culture Area. Societal Studies, 5, 501-514.

Petridis, P., Dunwell, I., Liarokapis, F., Constantinou, G., Arnab, S., Freitas, S., \& Hendrix, M. (2013). The Herbert Virtual 
Museum. Journal of Electrical and Computer Engineering, 2013, Article ID: 487970. http://dx.doi.org/10.1155/2013/487970

Ryan, N. S. (1996). Computer Based Visualisation of the Past: Technical "Realism” and Historical Credibility. In T. Higginsm, P. Main, \& J. Lang (Eds.), Imaging the Past (pp 95-108). British Museum Occasional Paper No. 114, London: British Museum Press.

Sánchez, J., Lumbreras, M., \& Silva, J. (1997). Virtual Reality and Learning: Trends and Issues. Proceedings of the 14th International Conference on Technology and Education, Oslo, 10-13 August 1997.

Schweibenz, W. (1991). The Virtual Museum: New Perspectives for Museums to Present Objects and Information Using the Internet as a Knowledge Base and Communication System. In H. Zimmermann, \& H. Schramm (Eds.), Knowledge Management und Kommunikationssysteme, Workflow Management, Multimedia, Knowledge Transfer. Proceedings of the 6th ISI Conference, Prague, November 1998 (pp. 185-200). Konstanz: UKV. http://www.informationswissenschaft.org/wp-content/uploads/isi/isi1998/14_isi-98-dv-schweibenz-saarbruecken.pdf

Second Life. Your World. Your Imagination. Accessed 20 September 2015. http://secondlife.com/

Sinthanayothin, C., Wongwaen, N., \& Bholsithi, W. (2012). Interactive Virtual 3D Gallery Using Motion Detection of Mobile Device. International Journal of Advancements in Computing Technology, 4, 239-250. http://dx.doi.org/10.4156/ijact.vol4.issue7.27

Solina, F. (2014). New Media Art Projects, Panoramic Images and Live Video as Interface between Real and Virtual Worlds. DESIDOC Journal of Library \& Information Technology, 34, 110-124. http://dx.doi.org/10.14429/djlit.34.6753

Sylaiou, S., Liarokapis, F., Kotsakis, K., \& Patias, P. (2009). Virtual Museums, a Survey and Some Issues for Consideration. Journal of Cultural Heritage, 10, 520-528. http://dx.doi.org/10.1016/j.culher.2009.03.003

Tsichritzis, D., \& Gibbs, S. (1991). Virtual Museums and Virtual Realities. Proceedings of International Conference on Hypermedia and Interactivity in Museums, Pittsburgh, 14-16 October 1991, 17-25.

Ullrich, T., \& Zara, J. (2002). Interactive Virtual Gallery. Proceedings of the 18th Spring Conference on Computer Graphics, Budmerice, 24-27 April 2002, 43-47. http://dx.doi.org/10.1145/584458.584466

Ulusoy, K. (2010). Open Education Students’ Perspective on Using Virtual Museum Application in Teaching History Subjects. The Turkish Online Journal of Distance Education, 11, 36-45.

Vosinakism, S., \& Xenakis, I. (2011). A Virtual World Installation in an Art Exhibition: Providing a Shared Interaction Space for Local and Remote Visitors. Proceedings of the Re-Thinking Technology in Museums, Limerick, 26-27 May 2011, 253-264.

Winslow, J. (1996). Multimedia and Virtual Reality in Instruction: Some Risk of Virtual Learning. Proceedings of EDMEDIA, Boston, 17-22 June 1996, 817.

Zoneta, A. (2010). Advertising Identities: Virtual Galleries as Places of Identity. Journal of Comparative Research in Anthropology and Sociology, 1, 169-186. 